\title{
Una mirada cotidiana desde la Psicología Positiva en un grupo de adultos mayores: relato de una experiencia
}

Manuel Sternik•

\section{Resumen}

En un intento de construir de manera colectiva un modo saludable de "estar siendo" en la vida, se constituyó en el año 2007 en la Sociedad Israelita de San Luis un grupo estable de quince adultos mayores que, bajo la coordinación de un psicólogo social, se reúne sistemáticamente una vez por semana. Dicho Proyecto de Intervención, psicoeducativo se propuso como finalidad generar un espacio de encuentro, discusión y reflexión donde los participantes pudiesen compartir sus experiencias existenciales, fortalecer los lazos comunicativos y revisar aquellas conductas que obstaculizan una adaptación activa a la realidad para, desde allí, consolidar aquellas cualidades positivas y conductas prosociales que pudieran impactar en su bienestar subjetivo.

Articulando los aportes de la Psicología Positiva y los de la Gerontología Crítica, a lo largo de la experiencia se fueron abordando diversos contenidos que podrían sintetizarse en los siguientes grandes ejes temáticos: Los procesos de subjetivación de los adultos mayores y la construcción de las identidades, el tránsito hacia la tercera edad como proceso vital, las actitudes negativas como modelo hegemónico en nuestra cultura, la prevención y promoción de la salud psíquica y el desarrollo de las cualidades positivas.

Con el presente trabajo nos proponemos dar cuenta del proceso generado a lo largo de dicha experiencia y de los cambios que se fueron visualizando en los posicionamientos subjetivos de los integrantes del grupo. Compartir los conocimientos construidos permitirá seguir reflexionando acerca de la necesidad de diseñar espacios y estrategias de intervención salugénicas destinadas a un sector específico de la población, como es el de los adultos mayores.

Palabras Clave: Adultos mayores - Prevención y promoción de la saludDesarrollo de cualidades positivas.

-Psicólogo social. Universidad Nacional de San Luis, Argentina. E-mail: manuelsternik@yohoo.com.ar 


\section{Abstract}

In an attempt to collectively build a healthy way of "being" in this life in the year 2007 a permanent group of fifteen elderly people started to meet in the Sociedad Israelita (Israeli Society) from San Luis, coordinated by a social psychologist, and they continue meeting systematically once a week. This psycho educational Project of Intervention aimed to generate a space for meeting, reflecting and discussing ideas, in which participants could share their existential experiences, strengthen their communication bonds and revise those behaviors that hinder an active adaptation to reality, with the purpose of consolidating those positive qualities and prosocial behaviors that could eventually have an impact on their subjective well-being.

In the implementation of this project, and with the contribution of Positive Psychology and Critic Gerontology, different contents were dealt with. These contents could be summarized into the following main points: subjectivation processes of elderly people and construction of their identities, the step forward towards the third age as a vital process, negative attitudes as the hegemonic model prevailing in our cultures, prevention and promotion of psychical health and development of positive qualities.

This paper is an attempt to give an account of the process generated along the experience aforementioned and of the changes that took place in the subjective positioning of the members of the group. Sharing the knowledge and experience acquired will allow the reflection in relation to the need of designing spaces and strategies of salugenic intervention aimed at a specific age group of the population: elderly people.

Key words: Elderly people - Health prevention and promotion - Development of positive qualities 
Si entendemos que todo conocimiento comienza con una buena pregunta que construimos para formularle a la realidad, a nosotros mismos; quizá la pregunta que guía este trabajo sería por el destino social de los sujetos que transitan la tercera edad $^{1}$, en tiempos de destitución de la subjetividad, tal como se califica a este momento histórico desde diversos campos de las ciencias sociales.

Partimos de entender que "una subjetividad es un modo de hacer en el mundo, es un modo de hacer con el mundo, un modo de hacer con lo real” (Corea \& Lewkowicz, 2005, p. 48). Sin embargo, desde nuestro contexto social se promueve una actitud pasiva frente a la vida y se nos propone transitarla sin que nada interrumpa esa aparente armonía, esa natural seguridad del día tras día. Así se van configurando sujetos cuyas historias transcurren con una familiaridad acrítica, desde la que pocas veces se interrogan acerca de cuál es su lugar en el universo, cuál el sentido de su existencia. Aparente armonía que, en muchos casos se desestabiliza cuando algún factor externo, o cuando algo del orden de lo psíquico irrumpe poniendo en cuestión las maneras habituales de responder a las exigencias de la vida y para las que los sujetos no encuentran respuestas adaptativas.

En un intento de construir de manera colectiva un modo saludable de estar siendo en la vida, se constituyó desde la Sociedad Israelita de San Luis un grupo de adultos mayores que, bajo la coordinación de un psicólogo social, se propuso como finalidad generar un espacio de socialización, de encuentro y reflexión, donde los participantes pudiesen compartir sus experiencias existenciales, fortalecer los lazos comunicativos y consolidar aquellas cualidades positivas y conductas prosociales que pudieran impactar en su bienestar subjetivo.

Con el presente trabajo nos proponemos dar cuenta del proceso generado a lo largo de dicha experiencia y de los cambios que se fueron visualizando en los posicionamientos subjetivos de los integrantes del grupo. Creemos que tomar distancia de la experiencia para objetivarla y desde allí construir conocimientos puede contribuir a diseñar espacios y estrategias de intervención salugénicas destinadas a un sector específico de la población, como lo son los adultos mayores.

1. Es un importante aclarar que actualmente dentro del campo de gerontología se está dando una discusión interesante en torno a los "modos de designar" este sector de la población. Acordamos que el lenguaje tiene poder performativo, por tanto cualquier categoría que se utilice puede producir deformaciones de la realidad. Provisoriamente recurrimos a "Adultos Mayores" aún sabiendo que esta designación acota la mirada acerca de la compleja problemática que ella aborda. 


\section{Algunas referencias que permiten contextualizar la experiencia}

Nos parece importante señalar que la problemática de los adultos mayores, la tercera edad, el envejecimiento, la longevidad está siendo resignificada desde distintos campos de las ciencias humanas. En este trabajo, asumimos los postulados de la Gerontología Crítica y los de la Psicología Positiva, en tanto ellos son complementarios a la hora de comprender el proceso histórico por el cual este sector de la población permaneció invisible, en tanto sujeto social con potencialidades para vivir la vida de manera plena.

Desde el campo social y aún desde algunas disciplinas siguen siendo dominantes los modelos biomédicos, biologistas y organicistas para caracterizar a los adultos mayores. Estos modelos centran la mirada en lo que se considera "normal” o “anormal”, "sano” o "enfermo" según la edad de los sujetos, recurriendo de este modo a parámetros biológicos universalmente válidos para todas las culturas y todos los tiempos. Esta perspectiva niega la influencia de los procesos psicosociales en la salud o enfermedad de los sujetos. Todo se reduce a un problema biológico.

La Gerontología Crítica pone en cuestión esta manera reduccionista y homogeneizante de entender al "otro", de clasificar y de tratar al adulto mayor como si sólo portase un cuerpo biológicamente sano o enfermo. Este campo del saber propone un nuevo modelo para entender la complejidad del ser humano, entendiendo que los adultos mayores antes que nada son sujetos que han construido sus vidas en un contexto socio-histórico determinado. La subjetividad se va configurando así en la compleja trama de vínculos y relaciones sociales, que fueron haciendo que cada psiquismo emerja con mayores o menores posibilidades de adaptarse activamente a la realidad (Moragas Moragas, 1998).

El concepto de "salud" se modifica radicalmente y se entiende que la misma tiene que ver con las condiciones de posibilidad de desarrollar al máximo las potencialidades para llevar una "vida buena” (Seligman, 2003). Esta vida buena, al igual que la entiende la Psicología Positiva, está relacionada con las capacidades de generar un bienestar psicosocial que permita a los individuos adaptarse activamente a las complejas, múltiples y cambiantes situaciones de la vida cotidiana. La salud se entendería como esa posibilidad de estar- bien, bien- estar consigo mismo, con los otros y con el micro y macro mundo que rodea a cada sujeto, esto es, lograr una calidad de vida que permita disfrutar de lo que se ofrece y se busca como proyecto de vida.

Por otro lado, el problema de la longevidad demostrado por la biomedicina con bases estadísticas sustentables, ha tornado visible la necesidad de ocuparse del problema del alargamiento de la vida y de los sujetos que tienen la oportunidad de situarse en ella. Hasta el presente, la mira de las políticas ha estado centrada en los 
niños, los adolescentes, los adultos de mediana edad, descuidando el último tramo de la vida, esto es la longevidad.

Sin embargo, no se trata de poner el acento en una u otra, sino que el juego debe abrirse para poder comprender el movimiento vital como un continuo y atender la especificidad de la vida humana en su situacionalidad existencial. En este sentido la Psicología Positiva ofrece herramientas teórico- conceptuales y de intervención para construir apuestas interdisciplinarias para mejorar la calidad de vida de quienes transitan la tercera edad y la longevidad. La mirada puesta en los aspectos salugénicos y en el estudio de las fortalezas psíquicas, fortalezas yoicas (Casullo, 2008), contribuye a construir una perspectiva integral del ser humano y a proponer el desarrollo de experiencias subjetivas positivas que permiten descentrarse de los aspectos patogénicos, tan fuertemente arraigados en nuestra cultura y esencialmente en aquellas disciplinas que, paradójicamente, se encuadran en el campo de la salud.

Hoy los adultos mayores transitan sus vidas en un contexto en que se han fracturado los lazos sociales de contención, respeto y solidaridad y en el que se privilegia la juventud como categoría referencial de la existencia humana. El sentimiento de aislamiento interpersonal y social, de vulnerabilidad, el apego a la "cultura de la queja", la conciencia de finitud, la posibilidad de la muerte; generan sufrimiento psíquico que conmueve los posicionamientos que se asumen frente a los acontecimientos de la vida cotidiana. Ello nos convocó a rastrear en los aportes de la Psicología Positiva para construir un espacio donde los sujetos pudiesen liberar sus emociones negativas y desde allí re-elaborar el trazado de sus recorridos vitales, recuperando el deseo de vivir de manera plena, fortaleciendo el diálogo, el altruismo, la solidaridad. El concepto de capital psíquico desarrollado por María Martina Casullo (2005) entendido como "ese conjunto de factores y procesos que permiten aprender a protegerse y sobrevivir, a generar fortalezas personales” (p. 16), fue iluminador al momento de pensar y llevar a cabo una experiencia de intervención con sujetos en estado de longevidad.

\section{La experiencia}

A mediados del año 2007 desde la Sociedad Israelita de San Luis se constituyó un grupo de aproximadamente 12 adultos mayores con el propósito de configurar un espacio de encuentro en el que se abordaran de manera colectiva diversos temas/problemas que atraviesan a este sector etario. Para llevar a cabo dicha experiencia, quienes conducían la Institución convocan al autor de este trabajo, que en su condición de psicólogo social y de su trayectoria de trabajo con adultos mayores, podría ayudar a sostener este espacio. A partir de ello, con la colaboración de una pedagoga, se elabora un Proyecto de Intervención, que se definió como un espacio psicoeducativo y desde el que, articulando los aportes de 
la Psicología Positiva y los de la Gerontología Crítica, los participantes pudiesen revisar aquellas conductas que obstaculizan una adaptación activa a la realidad que les toca vivir.

Finalmente el proyecto se denomina "Los procesos de comunicación como espacio para la reconstrucción de la identidad en los adultos mayores”. Siguiendo los principios de Sofía Vinogradov e Irvin Yalom (1996) el escenario grupal se configura como un instrumento poderoso para revisar, enriquecer, transformar las interacciones interpersonales y analizar el peso que tienen en el desarrollo psicológico. De allí, que el eje se centró en los procesos comunicacionales, como espacios simbólicos que mediatizan el pensar, el sentir, el hacer; puesto que comunicar lo que "nos pasa” abre la posibilidad de relegar la palabra a la acción.

Dicho grupo se caracteriza por su heterogeneidad tanto en edades (desde los 68 a los 84 años), como en orígenes socioeconómicos, en niveles de escolaridad y en ocupaciones (amas de casa, trabajadores independientes, jubilados de la docencia, entre otros). El mismo se reunió de manera sistemática desde el segundo semestre del año 2007, a lo largo del 2008 y continúa en el presente año a pedido de sus integrantes. El encuadre de trabajo se definió con un encuentro semanal de tres horas, manteniendo estable las coordenadas de espacio y tiempo, como así también, la estructura de las reuniones.

Al tratarse de un grupo con particulares características, como lo es el de estar transitando la tercera edad en un momento histórico/político particular, los objetivos se plantearon en términos de contribuir a construir y fortalecer aquellas conductas prosociales que configuran el bienestar subjetivo, al mismo tiempo que proporcionar una red de contención, socialización, educación y apoyo frente a situaciones hostiles que la cotidianeidad va generando.

La metodología elegida fue un Foro de encuentro, discusión y reflexión, en tanto, si bien se propusieron contenidos mínimos, en el proceso grupal los mismos se fueron redefiniendo en función de los emergentes y de las necesidades de los participantes. El coordinador tuvo la función de orientar y dirigir la conversación y ayudar a realizar síntesis integradoras que favorecieron la reflexión sobre aquellas problemáticas que preocupaban al grupo y que tendieron a la búsqueda de alternativas superadoras de posicionamientos estereotipados que impedían un mayor bienestar subjetivo.

En un proceso dialéctico se fueron profundizando cada vez más las temáticas abordadas, a fin de encontrar las razones que generaban las distintas situaciones por las que atravesaban los adultos mayores, poniendo en evidencia la fuerza del grupo en la construcción de la noción del "nosotros" como sostenedor y referente de las conflictivas individuales. 
En cada uno de los encuentros semanales la dinámica de trabajo se planteó en tres momentos:

1. Momento de problematización: en donde se decidía el tema a abordar en ese encuentro, se discutía, se reflexionaba desde las vivencias, perspectivas y visiones de cada uno de los participantes. Aquí se buscó crear un clima de confianza para que cada uno pudiera hablar desde el "sí mismo", escuchar al otro, aportar a la construcción de otras maneras de ver los problemas y desde allí revisar las propias posiciones y representaciones acerca del tema tratado.

2. Momento de recreación/distensión: se constituyó en un espacio de descanso y relajación donde se fortalecían los lazos sociales desde otros registros.

3. Momento de síntesis y cierre de la reunión: se buscaba construir una síntesis integradora de lo abordado. Si el tema ameritaba se pensaba de manera colectiva estrategias superadoras de las situaciones conflictivas y por último se realizaba una evaluación donde cada participante pudiese poner en palabras lo que había significado ese encuentro en relación a los aprendizajes subjetivos y donde se definía el tema del próximo encuentro.

En relación a los contenidos, si bien desde la coordinación se propuso un recorrido a seguir, éstos se fueron redefiniendo en función del devenir grupal y de los emergentes contextuales, que nos exigieron centrar la mirada en las demandas concretas para fortalecer procesos y estrategias promotoras de salud. Los mismos se podrían agrupar en las siguientes categorías:

Los procesos de subjetivación de los adultos mayores y la construcción de las identidades: ello nos permitió articular desde una mirada sociohistórica el análisis de aquellos procesos que van dando forma al devenir subjetivo en los mismos, los cambios que vivieron los participantes en relación a las configuraciones de los géneros, las relaciones intergeneracionales, las transformaciones en la organización de la vida cotidiana, en los procesos políticos, culturales, sociales y su impacto en los modos de envejecer dominantes en cada momento histórico.

El tránsito desde la tercera edad hacia la longevidad: por ser los participantes portadores de una historia y sujetos que transitan la tercera edad, se tornó indispensable compartir las vivencias, sentimientos, experiencias en relación a los posicionamientos que este proceso exige. Los aportes de la Gerontología Crítica nos permitieron analizar los significados sociales y subjetivos en relación a la “edad", las representaciones sociales acerca de lo que implica el envejecimiento, los prejuicios personales e intersubjetivos que condicionan las posibilidades de construir un estado de plenitud y bienestar psíquico (Neugarten, 1999). 
Las actitudes negativas como modelo hegemónico en nuestra cultura: en torno a este eje, se fueron tejiendo el análisis y la reflexión de los contenidos y significados dominantes de la cultura en la que nos hemos constituido como sujetos. Contenidos y significados que sobrevaloran los aspectos negativos, que potencian la "cultura del sufrimiento y de la queja”, que privilegia los aspectos patogénicos y que entiende que la salud sólo estaría garantizada si hay ausencia de enfermedad. Se problematizaron entonces, múltiples creencias arraigadas en los esquemas de pensamiento y acción de los participantes y se abordaron algunos sentimientos y actitudes negativas que impiden vivir una vida plena y en armonía con uno mismo y con el contexto. La soledad, la queja, el miedo, la inseguridad, el aislamiento, el autoabandono, la dependencia, la rigidez; el temor al anonimato, el sentimiento de fragmentación psíquica y social; fueron algunas de las actitudes y posicionamientos negativos que se tornaron visibles en un intento por comprender/nos y desentrañar las visiones de mundo que guían las prácticas cotidianas.

La prevención y promoción de la salud psíquica como modo de estar siendo y estar viviendo la historia individual: a la vez que se fue poniendo en cuestión las matrices culturales dominantes, el grupo fue instalando en la escena otros modelos de relación inter e intrasubjetivos. Se generaron diversas estrategias para fortalecer las relaciones interpersonales entre los miembros, la cohesión grupal y los procesos de autorreflexión y comunicación, como pilares básicos para fortalecer desde allí, conductas adaptativas frente a los riesgos de sufrimiento psíquico a los que somete la vida cotidiana a los adultos mayores. En este sentido, se trabajó en pos del fortalecimiento de cualidades positivas tales como: aprender a asumir los riesgos y transformarlos en desafíos, escuchar los propios deseos, reforzar los sentimientos de autoestima y confianza en las propias posibilidades, permitirse el humor, aprender a perdonar y perdonarse, desarrollar el altruismo y la gratitud, transformar la desesperanza en esperanza; lo que conlleva el desarrollo de miradas optimistas ligadas a la utopía, a la construcción de proyectos que permitan pensar y diseñar cómo se quiere envejecer. El concepto de "madurescencia" (Yuni \& Urbano, 2001) y las metáfora de la "mudanza” y la posibilidad de traspasar la "tranquera" (Sternik, 2008), se constituyeron en ideas fuerzas que transversalizaron todo el acontecer grupal. Ello implicaba generar actitudes abiertas al cambio, potenciar la tolerancia a la frustración, asumirse incompletos pero con potencialidades para realizar movimientos internos que permitan el pasaje de la dependencia a la autonomía, de la estereotipia a la salud.

Finalmente, todos estos contenidos estuvieron atravesados por una mirada situada “desde” y “en” los participantes y su situacionalidad histórica, esto es ser adultos mayores portadores de un capital psíquico, cultural, social, simbólico desde el que reposicionarse creativa y activamente en las relaciones sociales. 


\section{Algunos resultados parciales: recuperando las voces de los participantes}

La memoria nos permite almacenar recuerdos, es memoria activa, guarda recuerdos trascendentes, pero esos recuerdos nos sirven si nos permiten seguir viviendo cada día mejor. El querer seguir viviendo bien significa un desafío (...) yo creo que a nosotros se nos ve como trastos viejos, pero no es así tenemos vida y por eso podemos seguir aprendiendo $\left(\right.$ Edith $\left.^{2}\right)$.

Si bien desde la coordinación se propuso abordar como temas la construcción de la identidad y la memoria, ligada a los procesos de subjetivación de los adultos mayores, el grupo fue construyendo una mirada sociohistórica desde la que se iban analizando las diversas vivencias, situaciones, tópicos que emergían en el proceso.

Desde nuestra perspectiva el tema de la "identidad y la memoria" en los adultos mayores, cobra aún mayor riqueza en tanto implica introducir la pregunta acerca de "quienes somos", "qué significamos para los otros”, "qué lugar/es se nos asignan socialmente y cuáles asumimos implícita o explícitamente"; todo ello estrechamente vinculados a la historicidad subjetiva y social, a los vínculos y relaciones de género, al lugar de la familia; en definitiva al papel fundante de los otros como tejido, trama y sostén de los procesos de subjetivación. A través de diversas estrategias se fueron desnaturalizando aquellos referentes que pueblan la memoria, aquellos espacios sociales que configuran los sentidos de pertenencia a un tiempo histórico singular, aquellas significaciones y sentidos que dan forma a los sueños e ideales. Tal como sostiene Ana Quiroga (2005):

la historia social es el entramado en el que se da la construcción y sostén de la identidad. Esta encuentra su condición de autenticidad en la inscripción activa en ese proceso histórico, en la apropiación de su complejidad, con una modalidad que implique conciencia y protagonismo (p.43).

Abordar la problemática de la identidad implica referenciarla a la memoria, puesto que ésta va tomando forma en el seno de una relación siempre dinámica consigo mismo y con los otros. La memoria individual y colectiva, frecuentemente

2. Todos los nombres de los sujetos participantes, de aquí en adelante son ficticios con la intención de preservar la identidad de los mismos, aún cuando ellos han consentido en compartir su experiencia en el presente trabajo. 
en nuestro contexto social aparece ligada a discursos y prácticas referidas a la otredad, esto es a la necesidad de diferenciaciones sociales, culturales, históricas, de género, de edad, etc., desde donde se establecen categorías diferenciadoras, muchas veces portadoras de prejuicios. Sin embargo, si estas conceptualizaciones y representaciones se ponen en cuestión desde perspectivas críticas, permiten comprender ese sentido de continuidad y discontinuidad, de integración y diferencia que otorga sentido a la vida humana.

En el trabajo compartido fueron emergiendo los estigmas que los adultos mayores han internalizado acerca de sí mismos como historia viviente de la tercera edad y aquellos que circulan por el contexto social. Se desnaturalizaron así estereotipos como "la incapacidad", la "lentitud para pensar y actuar", "la decadencia”, "la intolerancia y el capricho", "el egocentrismo", como características y atributos propios de las personas mayores, producto de la declinación psicobiológica y se puso en cuestión el orden social y cultural que ayuda a configurar estas imágenes. Entre las estrategias a las que recurrimos para tornarlas visibles, podemos destacar el análisis de las propias representaciones, los discursos que circulan por los medios de comunicación, los íconos con los que se los caracteriza, las palabras con las que son nombrados en la familia o en el espacio social. Ello significó una importante movilización interna que permitió "darse cuenta” de cómo los sujetos participantes contribuyen a fortalecer esos estigmas y, en muchos casos, operan como obstáculos para configurar una imagen positiva de sí mismos, ligada a la posibilidad de una inserción activa y saludable a la comunidad.

La vejez, la tercera edad, son construcciones históricas y culturales, y las representaciones que se construyen en relación a los sujetos que la transitan van marcando posiciones y delimitando funciones y roles que se espera se jueguen en relación a determinadas regulaciones provenientes del contexto social. En este sentido, el grupo pudo comprender cómo la demarcación por “edades cronológicas” cumple una función de principio de clasificación de la población desde la que se puede prescribir qué se espera, qué es lo permitido y prohibido para cada edad. Principios de clasificación que tienden a homogeneizar y a limitar la libertad, la creatividad, la autenticidad, la posibilidad de disfrutar el presente por estar apegados a los mandatos externos. La voz de Gregorio, un participante, es elocuente en este sentido:

Con los adultos mayores la familia establece una relación de sobreprotección ubicando al otro en un estado de minusvalía. La familia aconseja lo que cree mejor para la persona sin tener en cuenta lo que ésta piensa. Por la edad se supone que tenemos valía disminuida y eso nos ata, nos impide que disfrutemos de lo que podemos hacer. 
Este trabajo, tratando de desentrañar los posicionamientos que se asumen y que se adscriben a la edad, introdujo la necesidad de abordar el concepto de "Mudanza" que fue cargándose de sentidos en el devenir del grupo. Si nos atenemos a su significado, "mudar" implica transformar un estado por otro// dejar una cosa por otra//trasladarse de un lugar a otro//cambiar//variar, modificar el comportamiento. Tal como sostiene la Psicología Positiva si bien los sujetos traen un bagaje genético, han aprendido determinadas conductas sociales en el tránsito de sus vidas, "todo es modificable", es posible torcer el destino social que se nos ha prefigurado según las posiciones que ocupamos en el contexto social, ya sean de género, de edad, de clase social, de origen cultural y religioso, entre otros. Hirsch señala que se puede aprender a ver lo positivo de cada situación. Hay personas que lo logran más fácilmente que otras; existen aquellos que lo hacen naturalmente, pero todos podemos entrenarlo por medio de distintos métodos, por ejemplo, la autoconciencia y el autoconocimiento, aprendiendo a identificar pensamientos negativos y cuestionándolos. Si tenemos en claro la propensión hacia el pensamiento negativo, somos concientes de la dificultad para ver lo positivo. Es un buen inicio. Desde esta perspectiva para poder aprender y aprehender modos de actuar, pensar y sentir positivos es fundamental que los sujetos puedan mudar, transitar un camino que les permita transformar sus miradas y perspectivas desde donde analizan y significan sus experiencias vitales. Cuando se propuso trabajar en torno al concepto de “mudanza” Delia, una de las integrantes del grupo, lo pudo expresar de este modo:

Yo pienso que la mudanza es movimiento. Nos puede costar, pueden producirse rupturas, puede haber conflicto interno, yo lo he vivido, a veces siento que no voy a poder cambiar mi manera de ver las cosas, pero lucho y lucho conmigo misma. Claro yo sé, como lo vimos acá que se dan períodos de avances y retrocesos, pero para que la mudanza se instale, para que busquemos el ser felices tenemos que instalarla como objeto mental, las ganas de estar bien tienen que ocupar un espacio mental.

La mudanza es movimiento interior que se materializa en la búsqueda del bienestar psíquico, en el bien-estar con el mundo. Ella nos implica en todo nuestro ser, nos desafía a rastrear cuánto hemos contribuido a sostener la idea de "la vejez" como una etapa terminal, de declinación y decadencia y a ocupar posiciones que acuden a victimizar a los adultos mayores. Perspectivas que no son ajenas a lo que ha ocurrido históricamente en el campo cultural y específicamente en los enfoques epistemológicos hegemónicos en la psicología. Tal como sostiene Beatriz Vera Poseck (2006b) "De forma histórica, la psicología ha concebido al ser humano como un sujeto pasivo, que reacciona ante los estímulos del ambiente” (p. 4), 
descuidando el potencial adaptativo que tienen los sujetos frente a situaciones que pudiesen resultar traumáticas o al menos situaciones que, sin ser profundamente dolorosas no aportan a generar un clima de armonía con la propia vida. De allí que el concepto de "mudanza" se convirtió en un concepto bisagra que permitió al grupo comenzar a visualizar las propias fortalezas, a la vez que revisar las emociones negativas que predominaron en sus maneras de ver el mundo. Elena, en uno de los encuentros reflexionaba en voz alta:

Hay que disfrutar lo que hemos logrado. Si no hubiera habido mudanza, ruptura, Lucía no hubiera llegado a esto que puede hacer hoy: manejar su propia vida (haciendo referencia a otra integrante que pudo decidir por sí misma quedarse a vivir en San Luis a pesar de su edad, cuando toda su familia la presionaba para que se fuese a Buenos Aires). Hemos alcanzado este grupo que es un logro de todos nosotros, disfrutamos con sentido positivo. Ver las cosas con el lente positivo, depende de nosotros.

Ligada a la idea de “mudanza” emergió la necesidad de poner en cuestión una emoción que puede resultar negativa en determinados contextos y situaciones, como lo es la nostalgia de un pasado que ya no es. Anclarse en el pasado es una tendencia fuerte en los adultos mayores, puesto que el refugio en los recuerdos, en cierto modo, reasegura no enfrentarse con los procesos de envejecimiento y con la posibilidad de la muerte propia o la de los congéneres. Sin embargo, esta mirada hacia atrás muchas veces cristaliza los acontecimientos, las experiencias, el tiempo histórico y los torna inmunes a las contradicciones, a las dualidades, a la complejidad de los hechos sociales, culturales, existenciales. Pareciera que la idealización de "lo que fue”, opera como mecanismo de defensa frente a la posibilidad de adversidades en el presente y la negación de un futuro que se presenta como incierto. Esta posición emergía en el grupo de manera frecuente, entonces se propusieron desde la coordinación diversas estrategias tendientes a desnaturalizarlas con el fin de ayudar a mirar el presente como un "tiempo/espacio de posibilidad". Entre ellas, nos parece interesante compartir una que resultó una buena experiencia para el grupo: se les propuso que recuperaran de su memoria anécdotas, recuerdos, imágenes, postales de la ciudad de San Luis de cuando ellos eran adolescentes o jóvenes.

A la vez que el pasado se hacía presente en la memoria colectiva, se tornaban visibles rasgos de la identidad de los sujetos y las búsquedas de anclaje en una ciudad que muchos reconocían alejada de "sus raíces". En los discursos emergía con fuerza la "cultura de la queja" puesta en la sensación de una ciudad que no los contiene, que no los cobija, que ha cambiado a un ritmo que los sujetos de la tercera edad no pueden procesar. Sin embargo, esto que podría ser leído como denuncia, emerge al mismo tiempo anunciando la necesidad de filiación a un nuevo espacio 
social. Así, se propuso realizar un recorrido por la ciudad para volver a reconocerse en este lugar, para analizar las posibilidades que brinda, cómo se configura la cotidianeidad, cuál es su modo de ser, cuáles los espacios que ofrece para el ocio y el esparcimiento, cuáles los límites entre lo público y lo privado, cómo se contempla o no desde su arquitectura a los adultos mayores. Luego de caminar por la ciudad observando, deteniéndose a registrar los cambios, comparando entre el ayer y hoy, el grupo se sienta a compartir un café en un bar. En la evaluación de esta experiencia, recuperamos algunas voces. Luisa, nos dice:

Es verdad, todo ha cambiado mucho y yo no lo quería ver. Yo me había enojado mucho cuando cerraron la calle Rivadavia para hacer una peatonal. Me acuerdo cuando me dirigía diariamente a la tintorería que tenía mi esposo en la calle Belgrano ¡cómo era de distinto el panorama! Ahora parece una ciudad multicultural porque se han mezclado varias culturas. Pero los mayores debemos pedir un reconocimiento mínimo, que nos tengan en cuenta al hacer las veredas, por ejemplo.

\section{A lo que Fernando agrega:}

Los adultos mayores tenemos que apoyarnos en el capital cultural que hemos construido, porque hemos vivido más, es nuestra historia vivida. Lo vivido forma parte del arsenal del pasado con que contamos y eso unido a la inteligencia, al entusiasmo, genera motivaciones en base a la creatividad. Por eso yo creo que podemos hacer cosas para ser reconocidos en los cambios que se hagan en la ciudad. Que no sea sólo para los jóvenes, que sea una ciudad para todos.

La construcción de una mirada diferente ante los cambios externos nos habla a su vez, de procesos internos que van viviendo los integrantes de este grupo. El reconocimiento que reclaman del afuera se traduce en un reconocimiento del "sí mismo", de esa continuidad necesaria de la identidad a pesar de los cambios en el tiempo y de las múltiples adaptaciones que la vida exige. De este modo, el grupo estaba atreviéndose a traspasar las fronteras de lo instituido como imagen social de lo que significa "envejecer", para abrir la tranquera $^{3}$ a nuevas perspectivas, a

3. La idea de "tranquera" ha sido tomada de la actividad agrícola ganadera y ella significa "puerta rústica hecha de troncos y palos"// "puerta de un cercado". En este caso no tomamos su significado en sentido literal sino como imagen, metáfora de aquello que limita un prado de otro, una parcela de tierra de otra y a la vez posibilita abrir el paso a otros espacios, a otros territorios cuando se tiene conciencia histórica de ser sujetos de la praxis. 
nuevas experiencias y por tanto a nuevas emociones, desconocidas hasta entonces.

El concepto de tranquera fue una construcción realizada en el interior del proceso grupal y que permitió simbolizar el tránsito-pasaje hacia otro estado superador, de bienestar psíquico en estado de longevidad. En este momento del curso vital, lo que está en juego es la temporalidad histórica; esto es la posibilidad de articular e integrar de manera coherente y satisfactoria el pasado, con el presente y con el futuro. Es ese tiempo de los acontecimientos vividos y el modo en que cada uno de los sujetos los resignifica, el que deja huellas, marcas en las maneras de percibir la vida, de valorarla y actuar en ella; el que abre o cierra tranqueras para desplegar aquello contenido como historia y poder ordenar cada sentimiento, cada emoción, cada experiencia particular de la manera más sana posible, de tal modo que el presente y el futuro puedan ser vividos como un tiempo de posibilidades y de desarrollo de las potencialidades humanas.

Tomando los postulados de la Psicología Positiva, se planteó trabajar en torno al concepto de "bienestar psíquico" y de "felicidad" en estado de longevidad. Se descompuso tal como propone Martín Seligman (2007) el concepto de vidas felices: la vida placentera, la buena vida y la vida con sentido, y se fueron trabajando cada una de ellas en distintos momentos del proceso grupal. Así, develar qué significa poder construir una vida placentera implicó que cada uno pudiese identificar aquellos factores, aquellas situaciones y experiencias con las que se sienten gratificados y a partir de allí diseñar disparadores de cómo se podrían ir atenuando aquellos aspectos de la vida cotidiana que generan displacer cultivando las emociones positivas. Este proceso, se entretejió con la necesidad de repensar qué significa llevar una buena vida en estado de longevidad, disfrutando de lo que se hace, viviendo con alegría, interrogándose acerca de lo que motiva el realizar determinadas tareas muchas veces adscriptas a la edad, a la posición o al género y que se las acepta sin cuestionar aún cuando privan a los sujetos adultos mayores de direccionar sus propias decisiones. Esto significó poner en cuestión el concepto de “abuelidad”, el lugar de las mujeres en el sostén de lo doméstico, el derecho al tiempo de ocio y de recreación muchas veces autonegado por exigirse asumir tareas que alivianen la vida de los hijos; entre otros mandatos culturales que van en detrimento de la propia capacidad de autodeterminación.

Finalmente, la vida con sentido y el sentido de la vida, se constituyeron en un eje de trabajo y reflexión permanente en el transcurso del trabajo compartido. Cada sábado, el grupo convoca a encontrarse con el otro, los miembros han podido construir la mutua representación interna y se llaman por teléfono, se sostienen cuando alguien no está bien, tanto física como emocionalmente, se aconsejan y en varias oportunidades propusieron realizar las reuniones en casa de alguno de ellos, ya sea para homenajearse, o cuando alguno por cuestiones de salud no podía 
desplazarse. Un hecho que permitió evaluar la construcción de pertenencia fue la decisión de asistir a un encuentro de adultos mayores en Embalse de Río Tercero. Muchos de los miembros no contaban con recursos económicos para costear el viaje y, sin embargo, todos pudieron asistir gracias a las solidaridades instauradas en el sentido de la vida de este grupo. Ello generó la realización de diversas actividades para conseguir el dinero necesario, pero al mismo tiempo la disposición para recrear actividades que pudiesen ser compartidas en dicho encuentro, tales como la preparación del póster donde se sintetizaba el quehacer del grupo, la planificación de actividades recreativas, entre otras y en las que cada uno fue dejando "su sello" personal, sus capacidades y destrezas. En la evaluación de la experiencia, todos dijeron su palabra, sólo recuperamos algunas que dan cuenta del impacto subjetivo que produce la felicidad auténtica:

La voz de Adela se escuchaba cuando decía: En las personas grandes las emociones impactan muy fuerte. La emoción puede tener base positiva, puede despertar circuitos que estaban dormidos, como las que sentimos en este encuentro.

Alfredo agregaba: este grupo fue reconocido al ser invitado. Es interesante salir para comprobar lo que tenemos de valioso en nuestro grupo, ies un lujo! Fue muy importante compartir la risa, el buen humor. El sentirse bien es salud.

A lo que Gladis añadía: Estamos en período de madurescencia y eso nos empuja a disfrutar, estar tranquilos, de hacer lo que le guste a cada uno. El que no lo hace, vive en soledad terrible. Ir a este encuentro nos puso en el lugar de ser protagonistas. Con estas actitudes, les estamos mostrando a las otras generaciones que somos continuadores de un eslabón de la vida.

Infundir la esperanza y poder adaptarse a las situaciones adversas fue otro desafío que el grupo tuvo que enfrentar. En el transcurso del 2008 dos miembros del grupo perdieron la vida. El concepto de resiliencia permitió trabajar un tema tan doloroso como este, en tanto allí se conjugaba el vacío y la ausencia de los que partieron con la posibilidad de la propia muerte. Las fortalezas del grupo, pusieron en evidencia que el trabajo realizado había permitido construir resiliencia, esto es sin negar el duelo, los sujetos pudieron sostenerse desde la tarea compartida, aprender y crecer a partir de estas situaciones límites. Los miembros del grupo no sólo lograron afrontar la muerte, sino que demostraron capacidad para salir íntegros de estas experiencias traumáticas reforzando los vínculos identificatorios, de cuidado del otro y de autoprotección. Algunas voces nos hablan de esta capacidad de adaptación: 
Gregorio decía: poder estar bien con nosotros mismos es la mejor forma de recordar y gratificar a quienes ya no están. Tenemos que darnos energía, cuidarnos entre nosotros. Necesitamos generar actividades para disfrutar de la vida. Este espacio de los sábados es salud, porque nos sentimos bien. Eso es salud: es sentirse bien con uno mismo y con los demás.

Y Adela agregaba: este espacio nos ayuda a afrontar la vida y la muerte. Si nos quedamos quietos ante los problemas que hemos tenido, no podríamos sobrellevar la carga y la ausencia de Rita y Pedro. Ellos seguramente nos pedirían que dejáramos descansar los problemas, que los recordemos con buen humor.

Tal como sostiene Beatriz Vera Poseck, (2006a):

Las experiencias traumáticas tienden a sacudir de forma radical las concepciones e ideas sobre las que se construye la forma de ver la vida (...). Cuando un individuo pasa por una experiencia traumática cambia su escala de valores y suele apreciar el valor de cosas que antes obviaba o daba por supuestas (p. 45).

El trabajo en torno a la muerte y al valor de la vida fue generando en los participantes una nueva mirada acerca de sus posicionamientos, de cuál es su "lugar en el mundo", cuál su tarea histórica y desde allí se fue fortaleciendo la necesidad de proyectarse en el presente y hacia el mañana. Desde la coordinación se valorizó la idea del "optimismo" como exigencia existencial de quienes transitan la longevidad. El optimismo remite a expectativas positivas y objetivos de futuro y cuya relación con variables como la perseverancia, el logro, la salud física y el bienestar (Peterson \& Bossio, 1991; Scheier \& Carver, 1993) promueve un sistema disposicional desde el cual potenciar la búsqueda del bienestar y generar conductas prosociales que favorezcan una adaptación activa a la realidad. En el trabajo colectivo se articuló “el optimismo" con la necesidad de "gerotrascendencia” en estado de longevidad, entendiendo que los sujetos cuentan con un capital psíquico desde el cual pueden proyectarse y poner en marcha acciones que devengan cada vez en metas de realización que son trascendentes. La trascendencia no se entiende aquí desde una perspectiva religiosa, sino desde la búsqueda de la superación, del desafío que implica interrogarse acerca del sentido de la vida y movilizarse hacia la construcción de buenas razones para vivir. La conciencia de la finitud característica en el estado de longevidad fue puesta en cuestión para, desde allí, construir el sentido de trascendencia asumiendo el presente con autonomía y decisión propia y como un tiempo de posibilidades. Algunas voces dan cuenta de este proceso: 
Gerardo decía: Los seres humanos somos portadores responsables de nuestro cuerpo. La vejez es la llegada a una estación pero después sigue el trayecto. Siempre se abre una puerta, una nueva posibilidad, si es que estamos dispuestos a mirar qué hay detrás. A mi, estar aquí, me ha generado un estímulo de esperanza para continuar adelante.

O la voz de Luisa cuando continuaba esta reflexión: Debemos asumir la responsabilidad psicológica de autoprevisión, con esta porción de apertura se pretende llegar más allá. Hay que prevenir, tomar recaudos. Tenemos que ir despacio y eso genera expectativas. El acto vital va y viene, no es rígido. Con la edad que tenemos, las cosas pasan vertiginosamente. Yo me pregunto ¿cuál es mi proyecto? Creo que nos estamos haciendo cargo de administrar lo nuestro, sin justificarnos en nuestras imposibilidades. Si le ponemos "pilas" hay protagonismo.

Y Edith cuando señalaba: Esta es la llave, "la tranquera”, poder dar un paso hacia delante, con la confianza de que podemos. Esto siento que me jerarquiza para tomar determinaciones sin conflicto ni arrepentimiento. (...) Nosotros somos los colonizadores de la longevidad. Somos sus nuevos habitantes.

En los estados de longevidad, como en cualquier instancia de la vida, creemos que es urgente devolverle a las emociones positivas su verdadero valor en los procesos subjetivos. En nuestro contexto, circula un fuerte mandato social por el cual los sentimientos y las emociones tienen que transcurrir en el mundo íntimo y privado del ser humano. Sin embargo, ellas marcan nuestras vidas, constituyen aquello que está en el fondo, en lo más profundo de lo que somos, y van dejando sus huellas en los modos de estar siendo en la vida. Esto nos impulsa a generar espacios donde las emociones positivas sean trabajadas, develadas, y tornarlas visibles para estar mejor consigo mismo y con el mundo que los rodea. Nuestro trabajo se centró en la desmitificación de lo que implica compartir las mismas, dejarlas ver, y desde allí ir fortaleciendo las potencialidades de despliegue y desarrollo de las emociones positivas y las conductas prosociales. Este espacio de intervención buscó integrar creativamente las emociones positivas al pensamiento y a la acción para poder reconciliarse con el mundo interno y construir un proyecto hacia donde caminar.

Como sujetos en estado de longevidad, pudimos comprender que es un momento que la vida nos regala y vivirla intensamente depende también de los espacios que se ofrezcan para reconocerse con potencialidades, con posibilidades concretas de transformar las emociones negativas en positivas. Convertir lo negativo en positivo, desarrollando estrategias de intervención basadas en lo que $a$ 
los sujetos les pasa, en sus alegrías, ilusiones, esperanzas; en su optimismo, en su capacidad de adaptarse a las situaciones adversas; es un camino que estamos construyendo de manera colectiva y en este andar la Psicología Positiva mucho nos ha aportado. Quizá una evidencia de ello fue la necesidad que tuvo el grupo de poder "nombrarse"; el nacer hacia fuera con un "nombre propio", ese que da identidad y que marca el destino hacia donde se quiere caminar. En una tarde de invierno del 2008, cuando el frío arreciaba la ilusión de sostener la vida del grupo, Laura una de las integrantes dijo:

Yo he pensado un nombre para este grupo, me parece que no podemos seguir llamándonos grupo de adultos mayores; es cierto somos eso pero mucho más, somos amigos de la esperanza, a mi me gustaría que nos pusiéramos un nombre así (el subrayado es nuestro).

Amigos de la Esperanza es nuestro grupo, allí aprendimos que la vida vale la pena vivirla intensamente y que es posible desarrollar una actitud positiva, que el altruismo, a pesar de los discursos individualistas engrandece al ser humano, que la alegría es esencial para desplegar la creatividad y sobre todo que ella nos empuja a estar juntos tejiendo redes solidarias, construyendo proyectos en los que el aporte de la singularidad de cada uno no implica la sumatoria de individualidades, sino que da como resultado una nueva construcción que es el todo grupal, el sentido de pertenencia a una comunidad. La voz de Andrés quizá sintetice lo que en este espacio se pretendió compartir:

Los nuevos habitantes de ese espacio somos nosotros. Somos habitantes de este espacio que se llama longevidad. Somos accionistas de nuestra propia empresa Debemos sentirnos orgullosos de eso.

\section{Bibliografía:}

Casullo, M. M. (2008) (comp.). Prácticas en Psicología Positiva. Buenos Aires: Lugar.

Casullo, M. M. (2005). El capital Psíquico. Aportes de la Psicología Positiva. En Revista Psicodebate 6. Buenos Aires. Universidad de Palermo

Corea, C. y Lewkowicz, I. (2005). Pedagogía del Aburrido. Buenos Aires: Paidós.

Moragas Moragas, R. (1998). Gerontología Social. Barcelona: Herder. 
Neugarten, B. (1999). Los significados de la Edad. Barcelona: Herder.

Peterson, C. \& Bossio, L. M. (1991). Health and optimism. New York: Oxford University Press.

Quiroga, A. (2005). Crisis, procesos sociales y grupo. Buenos Aires: Cinco.

Scheier, M, F. \& Carver, C. S. (1993). On the power os positive thinking: the benefits of being optimistic. Psychological Science, 2, 26-30.

Seligman, M. (2003). Authentic happiness ( ${ }^{\text {nd }}$. edition). London: Nicholas Brealey.

Seligman, M. (2007). Entrevista a Martin Seligman, director del centro de psicología positiva de Filadelfia. Diario “El Mundo”. Martes, 10 Febrero, 2007.

Sternik, M. (2008). La tranquera. Rescatando el pasado, Adueñándose del presente y decidiendo el futuro en Adultos Mayores. En Revista Tiempo. $N^{o} 23$. Buenos Aires.

Vera Poseck, B. y otros (2006a). La experiencia traumática desde la Psicología Positiva: resiliencia y crecimiento postraumático. En Papeles del Psicólogo. Vol. 27. Enero- Abril. Revista del Consejo General de Colegios oficiales del Psicólogo.

Vera Poseck, B. (2006b). La Psicología Positiva. Una nueva forma de entender la Psicología. En Papeles del Psicólogo. Vol. 27. Enero- Abril. Revista del Consejo General de Colegios oficiales del Psicólogo.

Vinogradov, S. y Yalom, I. (1996). Guía Breve de Psicoterapia de Grupo. Barcelona: Paidós.

Yuni, J. y Urbano, C. (2001). Mírame otra vez. Madurescencia femenina. Córdoba: Universidad Nacional de Córdoba. 
